\title{
Article \\ The Role of Cultural Capital on the Voluntary Contributions to Cultural Goods: A Differential Game Approach
}

\author{
Massimo Finocchiaro Castro ${ }^{1}$, Isidoro Mazza ${ }^{2}$ and Domenica Romeo ${ }^{1, * \mathbb{D}}$ \\ 1 Department of Law Economics and Social Sciences, Mediterranean University of Reggio Calabria, \\ via dei Bianchi 2, 89100 Reggio Calabria, Italy; massimo.finocchiaro@unirc.it \\ 2 Department of Economics and Business, University of Catania, 95129 Catania, Italy; imazza@unict.it \\ * Correspondence: domenica.romeo@unirc.it
}

Citation: Finocchiaro Castro, $\mathrm{M}$ Mazza, I.; Romeo, D. The Role of Cultural Capital on the Voluntary Contributions to Cultural Goods: A Differential Game Approach. Games 2021, 12, 27. https://doi.org/ $10.3390 / \mathrm{g} 12010027$

Academic Editors: Giovanna Bimonte and Ulrich Berger

Received: 26 January 2021

Accepted: 16 March 2021

Published: 18 March 2021

Publisher's Note: MDPI stays neutral with regard to jurisdictional claims in published maps and institutional affiliations.

Copyright: (c) 2021 by the authors. Licensee MDPI, Basel, Switzerland. This article is an open access article distributed under the terms and conditions of the Creative Commons Attribution (CC BY) license (https:/ / creativecommons.org/licenses/by/ $4.0 /)$.

\begin{abstract}
This study aims to offer a formal analysis which relates provision of cultural goods to the society's level of cultural capital. Such a level is assumed to already exist in society and is increasable thanks to individual support for the offer of cultural goods. The achievement of the highest levels of cultural capital increases satisfaction coming from cultural goods consumption, and then voluntary contributions. Social approval, deriving from donations, is positively related to society's existing cultural capital and triggers a positive externality for donators, thus increasing contributions and generating a positive externality for the whole society. The dynamic analysis provided in this study requires the adoption of a differential game where individuals interact, making their choices on their voluntary contribution level. We find that, under certain conditions, the solution obtained for the Nash equilibrium with closed-loop strategies provides optimal level of cultural capital that exceed the Pareto efficient solution obtained through open-loop strategies.
\end{abstract}

Keywords: public goods; cultural capital; voluntary offer; social approval; differential games

\section{Introduction}

Our work draws from an easily shareable statement: it is preferable to live in a society endowed with a high level of cultural goods. Translating the above assessment into economic terms, we can say that both the offer and the consumption of cultural goods generate a positive externality for society as a whole [1]. Often, such externalities are not fully internalised by subjects. Cultural goods consist of tangible or intangible items of cultural significance, such as heritage, works of art, literature, and music, etc. In the same vein, UNESCO [2] reported "cultural goods ... are the results of individual or collective creativity, include printed matter and literature, music visual arts, cinema and photography, radio and television, games and sporting goods".

In the case in question, as in the general case of pure public goods, leaving the job of supporting the supply of cultural goods up to individual contributions leads to inefficient levels of provision. In particular, for each subject, not to contribute to the cultural goods offer and enjoy the benefits is a dominant strategy. Despite this theorical assumption, positive levels of contribution of cultural goods are found in the real world. Economists provide several reasons for the benefits which individuals take from voluntary contributions. Among others, we can cite the pursuit of more prestige [3], of social approval [4], the 'warm glow' effect [5], and the principle of reciprocity [6]. The most significant effect resulting from subjects' choice to contribute is the accumulation of cultural capital, which Throsby [7] defined as "an asset that embodies, stores or provides cultural value in addition to whatever economic value it may possess". The accumulation of cultural capital increases, in turn, the stock of cultural capital, which refers to the quantity of such capital in existence at a given time.

In our model, we assume that individuals join the process of cultural capital accumulation both through voluntary contributions and tax payment which determine cultural 
capital in each period. However, as suggested by [8], a relevant portion of people may not be familiar with cultural goods. In order to fill this gap, investments in cultural education lead to cultural capital accumulation which results in a more cultivated society. In fact, society starting from initial higher levels of cultural capital results in a faster flow of cultural services [9]. In this regard, Molina et al. [10] showed that education level positively affects people's response to cultural matters. In fact, formal and informal education (e.g., training in any cultural activity) is found to be an important determinant of cultural-artistic consumption [11]. Additionally, we consider another crucial aspect for this model, which is "cultural sensitivity". In particular, greater quantities of cultural capital and individual contributions result in an increase in cultural sensitivity, meant both as greater attention to the public goods offer and a greater satisfaction resulting from cultural goods consumption. We fully acknowledge that the accumulation process deals with experiential goods carrying relevant positive externalities, being almost public goods [12]. However, although it is undeniable that the agents base their decisions of consumption of cultural goods on quality variables more than prices $[11,13,14]$, the investigation of the role of quality characteristics on cultural goods demand is beyond the scope of this paper.

Based on the above, we can imagine the establishment of a virtuous circle, as described in Figure 1. Indeed, a higher level of cultural sensitivity leads to a growing interest in cultural goods and a greater propensity towards such goods consumption. Given the premises, it becomes possible to witness an increase in individual voluntary contributions, which thus triggers an increase in the cultural goods private offer. Once more, such conditions allow for generating a higher level of cultural capital. Additionally, individual donators' choices to contribute are rewarded thanks to social approval by other members of society. The significance of the aforementioned aspect, able to modify individual behaviours, was largely put forward by both the theoretical [15-17] and experimental literature [18-20]. Clearly, the positive effects of social approval on cultural goods contribution level are boosted by a high level of cultural capital present in society.

Our model, based on the determinants of cultural capital suggested in the literature, examines the accumulation and the effects arising from an increase in cultural capital in a society, by using a dynamic approach. Analysing such accumulation mechanisms in detail, we attempt to better define the attention to cultural goods, $\left(\alpha_{i}\right)$. An increase in the level of attention, resulting from a higher level of cultural capital in the society, may increase the return on the voluntary offer in the same period. In fact, by increasing sensitivity towards culture, contributing subjects will receive greater social attention, which is expected to trigger economic benefits. Therefore, the accumulation of cultural capital also involves benefits to the whole society which are only partially internalized through the increase in the attention to cultural goods. Individuals also enjoy the mere existence of cultural activities (so called non-user benefits) even though they do not presently attend them [8]. To make an example, some people like living in a more cultivated society [9] and gain advantages from an increase in the number of theatres in their city, though not making use of them. Although these individuals draw benefits from the creation of cultural goods, they choose not to contribute to their offer. In addition, well-established experimental evidence shows that a portion of participants in public goods games play consistently as free-riders [21].

The purpose of this paper is, therefore, to provide a dynamic analysis of the cultural capital accumulation process. In particular, we attempt to explain the relationship between an increase in cultural capital and an increase in the voluntary provision of cultural goods. In fact, a greater level of cultural capital present in society increases the attention level towards cultural goods and, through social approval, encourages subjects to offer constantly growing contributions. Later, it is possible to determine the economy's optimal level of cultural capital which allows a society to reach the voluntary contribution equilibrium values. 


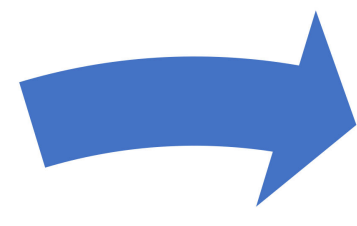 \\ Voluntary contributions to cultural goods cultural goods \\ Social approval \\ Cultural good production}
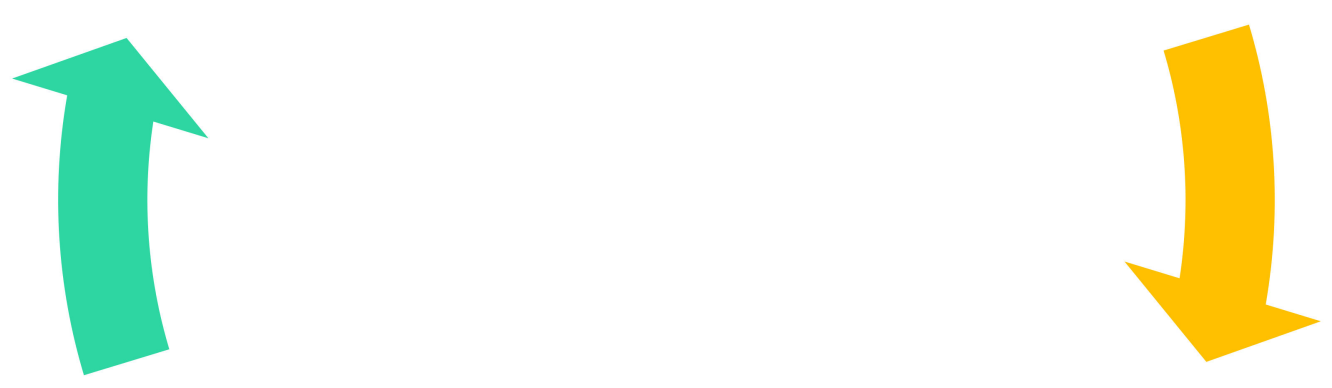

\section{Increase to cultural capital level}

\section{Sensitivity to cultural goods}

Greater level of cultural good voluntary offer Cultural good

Figure 1. Cultural goods and cultural capital virtuous circle.

\section{The Model}

Before starting with the formal analysis, it is useful to summarily conceptualise our model's underlying hypotheses for a better understanding of the mechanisms involved in the accumulation process of cultural capital:

- Cultural capital depends on both collective (taxes) and individual (voluntary contributions) investments in cultural goods. The mere presence of cultural goods cannot be considered sufficient to boost the accumulation of cultural capital in a society. Therefore, it is undisputed that there exist several factors which could be considered to explain the phenomena being studied. However, we decided to focus on only one of such factors: social approval. In fact, in addition to considering the presence of cultural goods, we analyse the effects resulting from the reward to anyone contributing to the offer of cultural goods, from the other society's members, which is social approval.

- The model includes only one type of public good, the cultural good. It is reasonable to assume that the sensitivity towards culture goods is related to the level of cultural capital obtained in each period by the society [22], together with the achieved voluntary contribution level. Moreover, such sensibility can affect both public choices and those of potential donators. However, for simplicity, we will focus only on individual choices, neglecting public choices about public goods financing.

- We assume that individuals can voluntarily contribute to the provision of public good and that such contribution causes a social reaction which depends on the society's cultural capital level which is positively assessed by the donator. Given such hypothe- 
ses, a cyclical mechanism with the following steps is formed: production of cultural goods $\rightarrow$ new cultural capital $\rightarrow$ social sensitivity level $\rightarrow$ new levels of voluntary contributions.

Now, we can move to the formal analysis of our model. Let us suppose that there is a society made of $n(n \geq 2)$ individuals (equilibria in games with a continuum of players resemble the limit of the corresponding equilibria in games with finitely many players [23]) identical in terms of preferences and income levels (for the sake of simplicity, we do not allow for heterogeneity of individuals' behaviour [24,25]). We imagine that each subject, who has an initial endowment, which is the same for every individual, at the beginning of each period has to decide how to allocate his resources among his consumption of private good, $x_{i}$, and his voluntary contribution to the offer of cultural good, $g_{i}$. The utility function is, then, the same for every subject,

$$
U_{i}=U\left(a_{i}, x_{i}, G\right)
$$

In this way, individual preferences are driven by attention to cultural good $\left(a_{i}\right)$, by the consumed amount of private good $\left(x_{i}\right)$, and by the total amount of the produced cultural $\operatorname{good}\left(G=\sum_{i=1}^{n} g_{i}\right)$.

The budget constraint which each subject must satisfy is given by:

$$
E_{i}=g_{i}+x_{i}
$$

Such constraint indicates how the whole initial endowment $\left(E_{i}\right)$, considered net of the taxes paid by every individual, must be allocated among consumption of the private good $\left(x_{i}\right)$ and contribution to cultural good $\left(g_{i}\right)$. However, it does not contain the term $a_{i}$, because it refers to a non-monetary factor, affecting individual preferences on cultural good allocations though.

Since we assume that individuals are identical, we can consider both the utility function and the budget constraint to be the same for all the subjects. Moreover, the utility function is the sum of three monotone and concave sub-utility functions, which makes it monotone and concave as well.

The utility function which measures the attention level to cultural capital is:

$$
u_{i}\left(a_{i}\right)=f\left(z_{i}, g_{i}\right)=\gamma z g_{i}
$$

Therefore, attention towards cultural capital is positively correlated with cultural capital, $z$, with the individual contribution level, $g_{i}$, and with the parameter $\gamma$ measuring individual's sensitivity towards cultural capital. It must be noticed that it is possible not to contribute to the provision of cultural goods and, thus, not to fully enjoy social approval, but at the same time to have the pleasant feeling coming from the presence of a higher level of cultural capital in the society.

The total quantity of cultural capital is obtained through the following linear production function:

$$
G=n\left(g_{i}+\tau_{i}\right)
$$

where, clearly, $n g_{i}$ is the total amount of voluntary contribution to cultural good, and $n \tau_{i}$ is the tax revenue which represents the compulsory contribution level established by the government. Therefore, the utility function, which refers to the amount of the offered cultural good, is given by:

$$
u_{i}(G)=\rho G-G^{2}
$$

By replacing the production function for the cultural capital (4) into (5), we obtain:

$$
u_{i}(G)=n\left(g_{i}+\tau\right)\left[\rho-n\left(g_{i}+\tau\right)\right]
$$


Finally, we assume the third utility function as:

$$
u_{i}\left(x_{i}\right)=E-\frac{\alpha}{2} g_{i}^{2}
$$

where $\alpha, 0<\alpha<1$, refers to individual propensity to voluntarily contribute to the cultural good. In order to investigate the evolution of voluntary contributions to changes in the economy cultural capital level, we use a differential game approach. To ensure the solvability of the problems defining the efficient and the equilibrium steady-state contributions and, in turn, to compare these levels, we assume that the sub-utilities are quadratic. In this way, the dynamic interaction can be described as a linear quadratic differential game [26]. Such a technique allows us to obtain and compare different equilibrium levels of the state variable in the case of Nash equilibrium with open-loop, feedback, or closed-loop strategies as well as Pareto efficient strategies, to changes in the individuals' interactions over time.

Indeed, open-loop strategies require that individuals own information only on the economy's initial state. Therefore, they are obliged to choose their strategies concerning the whole game in the starting period, without being allowed to change them later. Alternatively, feedback or closed-loop strategies depend on the time and the piece of information of the economy's current state. Consequently, individuals can change their strategy in every period, taking decisions after observing the system's current state. Notably, we refer to the voluntary offer of public goods models in dynamic context developed by van der Ploeg and de Zeeuw [27] and Fershtman and Nitzan [26].

\subsection{Open-Loop Outcomes}

Before obtaining Nash equilibrium with open-loop strategies, we first need to define the necessary conditions to the optimal control, using the Pontryagin's maximum principle. Given that, in this case, strategies only depend on time, we can write the individual's intertemporal maximization problem, making the sub-utility functions explicit:

$$
\begin{gathered}
\underset{g_{i}(t), c_{i}(t)}{\operatorname{Max} U_{i}} \int_{0}^{\infty} e^{-r t}\left[E-\frac{\alpha}{2} g_{i}^{2}(t)+n\left(g_{i}(t)+\tau\right)\left(\rho-n\left(g_{i}(t)+\tau\right)\right)+\gamma g_{i}(t) z_{i}(t)\right] d t \\
\text { s.t. } \dot{z}=n\left(g_{i}(t)+\tau\right)-\delta z(t), \\
z(0)=z_{0}
\end{gathered}
$$

where the dynamic equation for cultural capital (8) indicates how cultural capital level changes over time in the system as a function of contributions choices and the level of taxes decided by government which are exogenous. The evolution of capital value is also negatively correlated with the depreciation level $(\delta)$ of cultural capital of the previous period (i.e., constant in time). Finally, $z_{0}$ represents the system's initial state of cultural capital.

In order to find the level of cultural capital corresponding to the Nash equilibrium with open-loop strategies, we must write the Hamiltonian equation referred to the current value, $\aleph$, and necessary and sufficient conditions for a maximum,

$$
\begin{gathered}
g_{i}(t)=\operatorname{argmax} \aleph\left(t, g_{i}, z, \lambda\right), \\
\dot{\lambda}=\lambda(r+\delta)-\gamma g_{i}, \\
\lim _{t \rightarrow \infty} e^{-r t} \lambda(t)=0
\end{gathered}
$$

where $\lambda(t)$ is the co-state variable and $r>0$ is the intertemporal discount rate.

The Hamiltonian equation, then, will be:

$$
\begin{gathered}
\aleph=\left[E-\frac{\alpha}{2} g_{i}^{2}(t)+n\left(g_{i}(t)+\tau\right)\left(\rho-n\left(g_{i}(t)+\tau\right)\right)+\gamma g_{i}(t) z(t)\right] \\
+\lambda(t)\left[n\left(g_{i}(t)+\tau\right)-\delta z(t)\right]
\end{gathered}
$$


Maximizing (13) with respect to $g_{i}$ we obtain:

$$
\begin{aligned}
& g_{i}\left(\alpha+2 n^{2}\right)=\gamma z_{i}+n \rho-2 n^{2} \tau+n \lambda \Rightarrow \\
& \Rightarrow g_{i}=\frac{\gamma z_{i}+n \rho-2 n^{2} \tau+n \lambda}{\alpha+2 n^{2}}
\end{aligned}
$$

Since in the steady state $\dot{\lambda}=\dot{z}=0$, by replacing them, we get:

$$
\begin{gathered}
\dot{\lambda}=0 \Rightarrow \lambda=\frac{\gamma^{2} z_{i}}{(r+\delta)\left(\alpha+2 n^{2}\right)-n \gamma}+\frac{n \gamma(\rho-2 n \tau)}{(r+\delta)\left(\alpha+2 n^{2}\right)-n \gamma}, \\
\dot{z}=0 \Rightarrow z_{O}^{*}=\frac{n(r+\delta)(n \rho+\alpha \tau)-n^{2} \gamma \tau}{\delta(r+\delta)-n \gamma(r+2 \delta)}
\end{gathered}
$$

In this way, we obtain the optimal level $z_{0}$. By replacing in the first and second order conditions, solving for $g_{i}$, we obtain the corresponding equilibrium levels with open-loop strategies:

$$
g_{O}^{*}=\frac{n}{\alpha+2 n^{2}}\left\{(\rho-2 n \tau)+\frac{\gamma[(r+\delta)(n \rho+\alpha \tau)-n \gamma \tau]\left\{(r+\delta)\left(\alpha+2 n^{2}\right)+n \gamma^{2}(\rho-2 n \tau)[\delta(r+\delta)-n \gamma(r+2 \delta)]\right\}}{\left[(r+\delta)\left(\alpha+2 n^{2}\right)-n \gamma\right][\delta(r+\delta)-n \gamma(r+2 \delta)]}\right\}
$$

Now, we can calculate the Pareto efficient level of cultural capital, applying the same technique. The only difference lies in the fact that we consider the total sensitivity level towards cultural goods instead of individual levels. The Hamiltonian function will be:

$\aleph=\left[E-\frac{\alpha}{2} g_{i}^{2}(t)+n\left(g_{i}(t)+\tau\right)\left(\rho-n\left(g_{i}(t)+\tau\right)\right)+n \gamma g_{i}(t) z(t)\right]+\lambda\left[n\left(g_{i}+\tau\right)-\delta z(t)\right]$

First and second order conditions for Equation (18) become, respectively:

$$
\begin{gathered}
n \rho-\alpha g_{i}-2 n^{2}\left(g_{i}+\tau\right)+n \gamma z+n \lambda=0, \\
\dot{\lambda}=\lambda(r+\delta)-n \gamma g_{i}
\end{gathered}
$$

Replacing in the first and second order conditions and solving for $g_{i}$, we obtain:

$$
g_{i}^{*}=\frac{n \rho-2 n^{2} \tau+n \gamma z+n \lambda}{\alpha+2 n^{2}}
$$

Putting $g_{i}^{*}$ in steady state cultural capital equation, we can determine its optimal level, $z_{E}^{*}$

$$
\begin{gathered}
\lambda=\frac{n^{2} \gamma\left\{(r+\delta)\left(n^{2} \gamma \rho+n \alpha \tau\right)-n^{3} \gamma^{2} \tau+(\rho-2 n \tau)\left[\delta(r+\delta)\left(\alpha+2 n^{2}\right)-n^{2} \gamma(r+2 \delta)\right]\right\}}{\left[(r+\delta)\left(\alpha+2 n^{2}\right)-n^{2} \gamma\right]\left[\delta(r+\delta)\left(\alpha+2 n^{2}\right)-n^{2} \gamma(r+2 \delta)\right]} \\
z_{E}^{*}=\frac{n\left[(r+\delta)(n \rho+\alpha \tau)-n^{2} \gamma \tau\right]}{\delta(r+\delta)\left(\alpha+2 n^{2}\right)-n^{2} \gamma(r+2 \delta)}
\end{gathered}
$$

By comparing the equilibrium values obtained for Nash equilibrium with open-loop strategies (16) and that Pareto efficient (23), we can say that $z_{E}^{*}>z_{O}^{*}$. Noncooperative behaviour, which allows a society to achieve the economy's optimal individual level of cultural capital, does not allow to obtain the levels predicted for the Pareto efficient solution. Such a condition, in fact, requires that individuals have cooperative behaviours. However, it must be noticed that the existence of a maximum threshold for the parameter which represents the attention level towards cultural goods, at which the previously described inequality will not be satisfied, shows how it is possible to reach excessive levels of cultural capital so that a noncooperative solution becomes more efficient.

\subsection{Closed-Loop Outcomes}

Adopting the open-loop strategies, we carried out our analysis under the assumption that subjects can only observe the initial state of the game and that they do not know the 
other individuals' strategies. Therefore, their optimal choice is made in the first period and they are not allowed to change their decision until the end of the game. Since our model aims to analyse the effects of individuals' interactions throughout the game, it becomes necessary to make the strategies depend on not only time but also the system's state in each period. In our case, subjects can observe the level of cultural capital which is accumulated at the end of every step of the game. As a result, the new optimal level of cultural capital is a Nash equilibrium with closed-loop or feedback strategies. To obtain such equilibrium (which is also a subgame perfect equilibrium), we will draw from the technique used for linear programming.

We can now write the Hamiltonian-Jacobi-Bellman equation, and obtain the first order conditions which feature Nash equilibrium:

$$
r V_{i}(z, t)-\frac{\partial V_{i}(z, t)}{\partial t}=\max \left\{\begin{array}{l}
E-\frac{\alpha}{2} g_{i}^{2}+n\left(g_{i}(t)+\tau\right)\left(\rho-n\left(g_{i}(t)+\tau\right)\right)+\gamma g_{i}(t) z(t)+ \\
+\left[\frac{\partial V_{i}(z, t)}{\partial z}\right]\left[n\left(g_{i}+\tau\right)-\delta z\right]
\end{array}\right\}
$$

Assuming the following concave and quadratic value function [28]:

$$
V_{i}=\theta_{o}(t)+\theta_{1}(t) z-\frac{1}{2} \theta_{2}(t) z^{2}
$$

with $\theta_{2}(t)>0$

This allows us to obtain the maximum value for subject $i$ referred to the whole game started at $G(0)=G_{0}$, and we can thus obtain the closed-loop equilibrium strategies:

$$
g_{f}^{*}=\left(\frac{1}{\alpha+2 n^{2}}\right)\left[n \rho-2 n^{2} \tau+\gamma z+n\left(\theta_{1}-\theta_{2} z\right)\right]
$$

Replacing the obtained values and the value function in the Hamiltonian-JacobiBellman equation and putting $z$ and $z^{2}$ equal to 0 , we obtain two Riccati differential equations in $\theta_{1}$ and $\theta_{2}$. Taking together the parameter values for $\theta_{1}$ and $\theta_{2}$ (whose values are fully derived in Appendix A), the closed-loop equilibrium strategies and the accumulation function for cultural capital in the steady state, we determine the cultural capital level corresponding to the subgame perfect Nash equilibrium:

$$
z_{f}^{*}=\frac{n \tau\left(2 n^{2}+\alpha\right)+\left(n^{2} \rho-2 n^{3} \tau+n^{2} \theta_{1}\right)}{\delta\left(2 n^{2}+\alpha\right)-n \gamma+n^{2} \theta_{2}}
$$

where:

$$
\begin{gathered}
\theta_{2}=\frac{n \gamma-\left[(r+2 \delta-2 n \gamma)\left(\alpha+2 n^{2}\right)\right]}{n^{2}}>0 \\
\theta_{1}=\frac{(n \rho+\alpha \tau)\left[n-\left(\alpha+2 n^{2}\right)(r+2 \delta-2 n \gamma)\right]+n^{2} \gamma(2 n \tau-\rho)}{n(\delta-2 n \gamma)\left(\alpha+2 n^{2}\right)}>0
\end{gathered}
$$

Replacing the parameter values for $\theta_{1}$ and $\theta_{2}$ in the optimal level of cultural capital equation, we obtain:

$$
z_{F}^{*}=\frac{n^{2}\left\{n^{2} \gamma(2 n \tau-\rho)+n(n \rho+\alpha \tau)+\left(\alpha+2 n^{2}\right)(n \rho+\alpha \tau)[n \gamma-(r+\delta)]\right\}}{\left(\alpha+2 n^{2}\right)[2 n \gamma-(r+\delta)]}
$$

By comparing the Nash equilibrium with open-loop (16), closed-loop (29), and Pareto efficient strategies (23) for the optimal level of cultural capital, we can determine the following conditions:

$$
\begin{gathered}
\text { if }(r+\delta)<1 / 2, \\
\text { and, } \gamma>\frac{(n+\delta)(r+\delta)}{2 n+(r+\delta)}
\end{gathered}
$$

then $z_{F}^{*}>z_{E}^{*}>z_{O}^{*}$, otherwise $z_{E}^{*}>z_{F}^{*}>z_{O}^{*}$. 
This means that when individuals are given the opportunity to update their decisions throughout the game, after observing the optimal level of cultural capital accumulated at the end of every step, the obtained optimal level of cultural capital is higher than those reached through either the open-loop (16) or Pareto efficient (23) solution. However, this result holds only if conditions (30) and (31) are satisfied. In other words, this result holds with a reasonably low individual intertemporal discount rate and cultural goods depreciation rate. At the same time, the parameter $\gamma$, measuring individual sensitivity to cultural capital, has to exceed a given threshold. Using comparative statics, it appears that the sensitivity threshold is positively correlated to $r, \delta$, and $n$ (the latter holding when $r>\delta$ ). Alternatively, the inequality is partially reversed, meaning that, similar to what happens with open loop strategies, the levels predicted for the Pareto efficient solution exceed the level of cultural capital under the closed-loop strategy condition. In any case, regardless of conditions (30) and (31), the optimal level of cultural capital in the case of open-loop strategies is always lower that its correspondent level for the closed-loop strategies.

\section{Conclusions}

In order to investigate the evolution of voluntary contributions to changes in the economy's cultural capital level, we used the differential game approach. Such a technique allowed us to obtain and compare several equilibrium levels for the state variable in the cases of Nash equilibrium with open-loop, closed-loop or feedback and Pareto efficient strategies to changes in individuals' interactions over time. The starting idea is that subjects' utility resulting from the consumption of cultural goods depends on their initial endowment of cultural capital. In fact, as shown by Cheng [9], the greater the society's cultural capital, the broader the consumption of cultural goods. Additionally, we introduce another variable, which is crucial for the scope of our analysis, namely cultural sensitivity, which increases the satisfaction resulting from cultural goods consumption and, thus, stimulates individual voluntary contributions.

Our results show that under certain conditions, the solution obtained for the Nash equilibrium with closed-loop strategies provides a higher optimal level of cultural capital, even exceeding the Pareto efficient solution. Notably, whenever individuals can observe the level of cultural capital accumulated in each game period, their choices determine the highest possible level of cultural capital. The effect of cultural goods consumption on the accumulation of cultural capital has been also empirically investigated, among others, by Diniz and Machado [11]. They show that cultural consumption in Brazil is also affected by the level of consumers' education. Additionally, Castiglione and Infante [29] reported the addictive effect of past cultural goods consumption, such as demand for theatre, on current and future choices. Finally, based on an empirical analysis of touristic flows in Aosta Valley (Italy), Alderighi and Lorenzini [30] showed that when cultural capital accumulation is relevant, tourists are willing to give up some of their current utility in order to get higher returns in future.

From a policy perspective, our result is significant from two points of view. First, we provide support to the fundamental role of investing in cultural capital. For instance, by enhancing the opportunity to make the highest number of individuals in a society experience cultural goods, policy makers can increase the positive attitude towards cultural goods, and, in turn, the level of voluntary contributions to the provision of cultural goods. Second, it implies that when individuals are made aware of the society's cultural capital level, their decisions to contribute to the provision of cultural goods can lead to better solutions than when they blindly choose. Since the consumption and the creation of cultural goods benefits the whole of society [9], introducing a more accessible information system which spreads data on the society's changes in cultural capital level could drive subjects to make better choices in terms of their individual voluntary contributions, which, in turn, increase the level of cultural capital, thus creating a more cultivated society. 
Author Contributions: Conceptualization, M.F.C., I.M. and D.R.; Methodology, I.M.; Formal analysis, M.F.C.; Writing-original draft preparation, M.F.C. Writing-review and editing, D.R. All authors have read and agreed to the published version of the manuscript.

Funding: This research received no external funding.

Institutional Review Board Statement: Not applicable.

Informed Consent Statement: Not applicable.

Data Availability Statement: Not applicable.

Conflicts of Interest: The authors declare no conflict of interest.

\section{Appendix A}

Closed-Loop Outcomes

Let us replace the steady state individual contribution level to the cultural good, $g_{f}^{*}$, and the value function in the Hamiltonian-Jacobi-Bellman equation:

$$
\begin{gathered}
-r \theta_{0}-r \theta_{1} z+r \frac{1}{2} \theta_{2} z^{2}+\left[E-g^{2}\left(\frac{\alpha}{2}+n^{2}\right)+g\left(n \rho-2 n^{2} \tau\right)+\gamma g z+n \tau \rho-n^{2} \tau^{2}+\right. \\
\left.\left(\theta_{1}+-\theta_{2} z\right)(n g+n \tau-\delta z)\right]=0 \Longrightarrow
\end{gathered}
$$

$-r \theta_{0}-r \theta_{1} z+r \frac{1}{2} \theta_{2} z^{2}+\left[E-\frac{\left(\rho n-2 n^{2} \tau+\gamma z+n \theta_{1}-n \theta_{2} z\right)^{2}}{\left(\alpha+2 n^{2}\right)^{2}}\left(\frac{\alpha}{2}+n^{2}\right)+\left(\frac{\rho n-2 n^{2} \tau+\gamma z+n \theta_{1}-n \theta_{2} z}{\alpha+2 n^{2}}\right)(n \rho-\right.$

$\left.2 n^{2} \tau+\right)\left(\frac{\rho n-2 n^{2} \tau+\gamma z+n \theta_{1}-n \theta_{2} z}{\alpha+2 n^{2}}\right) \gamma z+n \tau \rho-n^{2} \tau^{2}+\left(\frac{\rho n-2 n^{2} \tau+\gamma z+n \theta_{1}-n \theta_{2} z}{\alpha+2 n^{2}}\right) n \theta_{1}+n \theta_{1} \tau-\delta \theta_{1} z-$

$\left.n \theta_{2} z\left(\frac{\rho n-2 n^{2} \tau+\gamma z+n \theta_{1}-n \theta_{2} z}{\alpha+2 n^{2}}\right)-n \tau \theta_{2} z+\delta \theta_{2} z^{2}\right]=0$

After some tedious algebra, we get:

$$
\begin{gathered}
r \frac{1}{2} \theta_{2} z^{2}-r \theta_{1} z-r \theta_{0}+E+ \\
\frac{\frac{1}{2} n^{2} \rho^{2}+\frac{1}{2} \gamma^{2} z^{2}+\frac{1}{2} n^{2} \theta_{1}^{2}+\frac{1}{2} n^{2} \theta_{2}^{2} z^{2}-2 n^{3} \rho \tau+2 n^{4} \tau \gamma z+n \gamma \rho z-2 n^{2} \tau \gamma z-2 n^{3} \tau \theta_{1}+2 n^{3} \tau \theta_{2} z}{\alpha+2 n^{2}}+ \\
\frac{n^{2} \rho \theta_{1}-n^{2} \rho \theta_{2} z+\gamma n \theta_{1} z-n \gamma \theta_{2} z^{2}-n^{2} \theta_{1} \theta_{2} z}{\alpha+2 n^{2}}+n \tau \theta_{1}-\delta \theta_{1} z-n \tau \theta_{2} z+\delta \theta_{2} z^{2}-n \rho \tau-n^{2} \tau^{2}=0
\end{gathered}
$$

Collecting the terms with $z$ and $z^{2}$ and setting them equal to 0 , we obtain two Riccati differential equations in $\theta_{1}$ and $\theta_{2}$.

$z^{2}\left(r \frac{1}{2} \theta_{2}+\frac{\frac{1}{2} \gamma^{2}+\frac{1}{2} n^{2} \theta_{2}^{2}-n \gamma \theta_{2}}{\alpha+2 n^{2}}+\delta \theta_{2}\right)+z\left(-r \theta_{1}+\frac{n \gamma \rho-2 n^{2} \tau \gamma+2 n^{3} \tau \theta_{2}-n^{2} \rho \theta_{2}+\gamma n \theta_{1}-n^{2} \theta_{1} \theta_{2}}{\alpha+2 n^{2}}-\delta \theta_{1}-n \tau \theta_{2}\right)=0$

Considering the first group of terms:

$$
\begin{gathered}
r \frac{1}{2} \theta_{2}+\frac{\frac{1}{2} \gamma^{2}+\frac{1}{2} n^{2} \theta_{2}^{2}-n \gamma \theta_{2}}{\alpha+2 n^{2}}+\delta \theta_{2}=0 \\
2\left(\alpha+2 n^{2}\right)\left(r \frac{1}{2} \theta_{2}+\delta \theta_{2}\right)+\gamma^{2}+n^{2} \theta_{2}^{2}-2 n \gamma \theta_{2}=0 \\
n^{2} \theta_{2}^{2}+\theta_{2}[r+2(\delta-n \gamma)]\left(\alpha+2 n^{2}\right)+\gamma^{2}=0
\end{gathered}
$$

The last quadratic equation has two solutions, namely

$$
\theta_{2,1}=-\frac{\gamma}{n}<0 ; \theta_{2,2}=\frac{n \gamma-\left[(r+2 \delta-2 n \gamma)\left(\alpha+2 n^{2}\right)\right]}{n^{2}}>0, \text { with } r+2 \delta<2 n \gamma
$$

Given that we have assumed $\theta_{2}>0$, we choose solution $\theta_{2,2}$.

Considering the second group of terms and after some algebra, we get:

$$
\theta_{1}=\frac{(n \rho+\alpha \tau)\left[n-\left(\left(\alpha+2 n^{2}\right)(r+2 \delta-2 n \gamma)\right)\right]+n^{2} \gamma(2 n \tau-\rho)}{n\left(\alpha+2 n^{2}\right)(\delta-2 n \gamma)}>0 \text {, with } 2 n \tau>\rho
$$


Taking together the parameter values for $\theta_{1}$ and $\theta_{2}$, the closed-loop equilibrium strategies and the accumulation function for cultural capital in the steady state, we determine the cultural capital level corresponding to the subgame perfect Nash equilibrium

$$
\begin{gathered}
\dot{z}=\frac{n}{\left(\alpha+2 n^{2}\right)}\left(n \varrho-2 n^{2} \tau+n \theta_{1}\right)+n \tau+z\left(\frac{n \gamma-n^{2} \theta_{2}}{\left(\alpha+2 n^{2}\right)}-\delta\right) \\
\dot{z}=0 \Longrightarrow z\left(\delta-\frac{n \gamma-n^{2} \theta_{2}}{\left(\alpha+2 n^{2}\right)}\right)=n \tau+\frac{\left(n \varrho-2 n^{2} \tau+n \theta_{1}\right)}{\left(\alpha+2 n^{2}\right)} \\
z^{*}=\frac{n \tau\left(\alpha+2 n^{2}\right)+\left(n \varrho-2 n^{2} \tau+n \theta_{1}\right)}{\delta\left(\alpha+2 n^{2}\right)-n \gamma+n^{2} \theta_{2}} \\
z^{*}=\frac{n \tau\left(\alpha+2 n^{2}\right)+\left(n \varrho-2 n^{2} \tau+n \frac{(n \rho+\alpha \tau)\left[n-\left(\left(\alpha+2 n^{2}\right)(r+2 \delta-2 n \gamma)\right)\right]+n^{2} \gamma(2 n \tau-\rho)}{n\left(\alpha+2 n^{2}\right)(\delta-2 n \gamma)}\right)}{\delta\left(\alpha+2 n^{2}\right)-n \gamma+n^{2} \frac{n \gamma-\left[(r+2 \delta-2 n \gamma)\left(\alpha+2 n^{2}\right)\right]}{n^{2}}}
\end{gathered}
$$

After the usual tedious algebra, we get:

$$
\begin{gathered}
z^{*}=\frac{n\left(\alpha+2 n^{2}\right)(\delta-n \gamma)(n(\alpha \tau+n \rho))+n^{3}(\alpha \tau+n \rho)-n^{2}(\alpha \tau+n \rho)\left(\alpha+2 n^{2}\right)(r+2 \delta-2 n \gamma)+n^{4} \gamma(2 n \tau-\rho)}{\left(\alpha+2 n^{2}\right)[2 n \gamma-(r+\delta)]} \\
z^{*}=\frac{n^{2}\left\{n^{2} \gamma(2 n \tau-\rho)+n(\alpha \tau+n \rho)+(\alpha \tau+n \rho)\left(\alpha+2 n^{2}\right)[n \gamma-(r+\delta)]\right\}}{\left(\alpha+2 n^{2}\right)[2 n \gamma-(r+\delta)]}>0
\end{gathered}
$$

\section{References}

1. Pethig, R.; Cheng, S.-W. Cultural capital and the consumption of cultural services, Schmollers Jahrbuch: Zeitschrift fur Wirtschaftsund Sozialwissenschaften. J. Appl. Soc. Sci. Stud. 2002, 122, 445-468.

2. UNESCO. International Flows of Selected Cultural Goods; UNESCO Institute for Statistics: Paris, France, 2000; Available online: http://www.unesco.org/statistics (accessed on 28 February 2021).

3. Harbaugh, W.T. The prestige motive for making charitable transfers. Am. Econ. Rev. 1998, 88, 277-282.

4. Mazza, I. A microeconomic analysis of patronage and sponsorship. In Cultural Economics and Cultural Policies; Springer: Dordrecht, The Netherlands, 1994; pp. 35-53.

5. Andreoni, J. Toward a theory of charitable fund-raising. J. Political Econ. 1998, 106, 1186-1213.

6. Sugden, R. Reciprocity: The supply of public goods through voluntary contributions. Econ. J. 1984, 94, 772-787.

7. Throsby, D. Cultural capital. J. Cult. Econ. 1999, 23, 3-12.

8. Frey, B.S. Arts Economics. Analysis Cultural Policy; Springer: Berlin/Heidelberg, Germany; New York, NY, USA, 2003.

9. Cheng, S.W. Cultural goods creation, cultural capital formation, provision of cultural services and cultural atmosphere accumulation. J. Cult. Econ. 2006, 30, 263-286.

10. Molina, J.A.; Campaña, J.C.; Ortega, R. Time Dedicated by Consumers to Cultural Goods: Determinants for Spain; MPRA WP 68430; RePEc: Munich, Germany, 2015.

11. Diniz, S.C.; Machado, A.F. Analysis of the consumption of artistic-cultural goods and services in Brazil. J. Cult. Econ. 2011, 35, $1-18$.

12. Meleddu, M.; Pulina, M.; Ladu, M.G. Evaluating the demand for cultural goods: Just income and tastes do matter? Econ. Della Cult. 2013, 23, 203-216.

13. Throsby, C.D. Perception of Quality in Demand for the Theatre. J. Cult. Econ. 1990, 14, 65-82.

14. Throsby, D. Determining the value of cultural goods: How much (or how little) does contingent valuation tell us? J. Cult. Econ. 2003, 27, 275-285.

15. Akerlof, G.A. A theory of social custom, of which unemployment may be one consequence. Q. J. Econ. 2003, 94, 749-775.

16. Bernheim, B.D. A theory of conformity. J. Political Econ. 1994, 102, 841-877.

17. Dufwenberg, M.; Lundholm, M. Social norms and moral hazard. Econ. J. 2001, 111, 506-525.

18. Gächter, S.; Fehr, E. Collective action as a social exchange. J. Econ. Behav. Organ. 1999, 39, 341-369.

19. Masclet, D.; Noussair, C.; Tucker, S.; Villevail, M.C. Monetary and nonmonetary punishment in the voluntary contributions mechanism. Am. Econ. Rev. 2003, 93, 366-380.

20. Rege, M.; Telle, K. An Experimental Investigation of Social Norms; Discussion Papers, No. 310; Statistics Norway, Research Department: Oslo, Norway, 2001. 
21. Ledyard, J.O. Public Goods: A Survey of Experimental Research. In Handbook of Experimental Economics; Kagel, J.H., Roth, A.E., Eds.; Princeton University Press: Princeton, NJ, USA, 1995.

22. Yamamoto, Y.; Brinton, M.C. Cultural capital in East Asian educational systems: The case of Japan. Sociol. Educ. 2010, 83, 67-83.

23. Wiszniewska-Matyszkiel, A. Open and Closed Loop Nash Equilibria in Games with a Continuum of Players. J. Optim. Theory Appl. 2014, 160, 280-301.

24. Ateca-Amestoy, V. Determining heterogeneous behavior for theater attendance. J. Cult. Econ. 2008, 32, $127-151$.

25. Brito, P.; Barros, C. Learning-by-consuming and the dynamics of the demand and prices of cultural goods. J. Cult. Econ. 2005, 29, 83-106.

26. Fershtman, C.; Nitzan, S. Dynamic voluntary provision of public goods. Eur. Econ. Rev. 1991, 35, 1057-1067.

27. Van der Ploeg, F.; de Zeeuw, A. A differential game of international pollution control. Syst. Control Lett. 1991, 17, 409-414.

28. Dockner, E.; Jørgensen, S.; Van Long, N.; Sorger, G. Differential Games in Economics and Management Science; Cambridge University Press: Cambridge, UK, 2000.

29. Castiglione, C.; Infante, D. Rational addiction and cultural goods: The case of the Italian theatregoer. J. Cult. Econ. 2016, 40, 163-190.

30. Alderighi, M.; Lorenzini, E. Cultural goods, cultivation of taste, satisfaction and increasing marginal utility during vacations. J. Cult. Econ. 2012, 36, 1-26. 